\title{
Flavonoid profile and antioxidant activity of pink guava
}

\author{
Khalid Hamid Musa ${ }^{\mathrm{a}, *}$, Aminah Abdullah ${ }^{\mathrm{a}}$, Vimala Subramaniam ${ }^{\mathrm{b}}$ \\ a School of Chemical Sciences and Food Technology, Faculty of Science and Technology, \\ Universiti Kebangsaan Malaysia, 43600 Bangi, Selangor, Malaysia \\ b Medicinal Plant Program, Biotechnology Division, Forest Research Institute Malaysia (FRIM), Kepong, \\ Selangor, Malaysia
}

*Corresponding author, e-mail: khalid.hamid@ukm.edu.my

Received 26 Jan 2015

Accepted 23 Mar 2015

\begin{abstract}
This article determines ascorbic acid, total phenolic content and the antioxidant capacity of whole fruit, flesh, and skin fractions of two varieties of pink guava widely produced in Malaysia (semenyih and sungkai). They were analysed and specific flavonoid compounds (apigenin, isorhamentin, kaempferol, luteolin, myricetin, and quercetin) were determined. Ascorbic acid, total phenolic content and antioxidant capacity was found to be higher in semenyih than in sungkai, mainly in the skin fraction. The predominant flavonoid in all pink guava fractions was kaempferol, with sungkai flesh having the highest kaempferol content. The pink guava represents an important source of antioxidant flavonoid compounds that may have health benefits.
\end{abstract}

KEYWORDS: Psidium guajava, variety, DPPH, FRAP

\section{INTRODUCTION}

Several studies to determine the relationship between fruits and health have found that eating five or more servings of fruit and vegetables daily might reduce the chance of disease incidence ${ }^{1,2}$. Since fruits and vegetables provide a mixture of phytochemicals, a hypothesis on the role of antioxidants in protective against chronic diseases has been proposed $^{3}$.

Guava (Psidium guajava) is one of the most important commercial fruit crop in tropical and subtropical countries and claims superiority over different fruits by virtue of its commercial and nutritional values. Guava is considered a common man's fruit and is called the 'apple of the tropics' 4 . Guava, like many other fruits and vegetables, is rich in antioxidant compounds such as polyphenols ${ }^{5}$, ascorbic acid $^{6}$, and carotenoids ${ }^{7}$. The chemical composition of the fruits depends on factors such as variety, maturity and the environmental conditions within which they are grown ${ }^{8,9}$.

The objective of this study was to report the antioxidant activities of two varieties of Malaysian pink guava. Selected flavonoid compounds were quantified (apigenin, isorhamentin, kaempferol, luteolin, myricetin, and quercetin). Various functions and actions such as antioxidants and anticarcinogens have been attributed to flavonoid compounds, making determination of their concentrations in food highly desirable.

\section{MATERIALS AND METHODS}

\section{Samples}

Two varieties of Malaysian pink guava namely sungkai and semenyih were collected from Perak State, Malaysia. Samples were transferred in ice on the same date to the Food Analysis Laboratory, University Kebangsaan Malaysia. The estimated time of transportation was about $4 \mathrm{~h}$. For the purposes of this study approximately 20 fruits pooled sample portion (taken from a 60 sample lot) were used on the same day.

\section{Physicochemical properties}

Fruit weight and seed weight were measured using digital balance (SK-5001, A\&D, Japan). The flesh weight was computed by subtracting seed weight from fruit weight. The fruit volume was determined by water displacement $(\mathrm{ml})$ and specific gravity was calculated by dividing the weight of the fruit by the volume of the fruit. To determine the titratable acidity (TTA), samples were crushed and blended in a Waring blender (USA). Ten ml of blended samples were diluted with $50 \mathrm{ml}$ of water before titrated with $0.1 \mathrm{~N} \mathrm{NaOH}$ and calculated as percent citric acid. Blended undiluted sample was used to measure the total soluble solids, results were expressed as Brix using Abbe refractometer at $20^{\circ} \mathrm{C}$ and the $\mathrm{pH}$ was determined using a $\mathrm{pH}$ meter from the undiluted samples. Lycopene was extracted using a mixture 
of acetone, ethanol, and hexane ${ }^{10}$. For L. ascorbic acid determination, $1 \mathrm{~g}$ was extracted with $25 \mathrm{ml}$ $1 \%$ cold metaphosphoric acid and determined using spectrophotometer ${ }^{11}$.

\section{Extraction of antioxidants}

Fruits were deseeded and the skins were removed using fruit peeler to get skin and flesh fraction as well as whole fruit. Samples were extracted with $50 \%$ aqueous acetone ${ }^{12}$.

\section{Total phenolic contents}

A $100 \mu \mathrm{l}$ aliquot of fivefold diluted pink guava extract was oxidized with diluted Folin-Ciocalteu reagent $(500 \mu \mathrm{l})$. After $5 \mathrm{~min}$, the mixture was neutralized with $1 \mathrm{ml} \mathrm{Na} \mathrm{CO}_{3}(8 \%, \mathrm{w} / \mathrm{v})$, and incubated for $120 \mathrm{~min}$ before reading absorbance at $765 \mathrm{~nm}^{13}$.

\section{Ferric reducing antioxidant power (FRAP)}

The FRAP assay method of Benzie and Strain ${ }^{14}$ was modified to determine antioxidant activity using trolox as the standard. The FRAP reagent was prepared using $300 \mathrm{mM}$ acetate buffer, $\mathrm{pH} 3.6$ (3.1 g sodium acetate trihydrate, plus $16 \mathrm{ml}$ glacial acetic acid made up to 11 with distilled water). The acetate buffer was mixed with $10 \mathrm{mM}$ TPTZ $(2,4,6-$ tri(2-pyridyl)-s-triazine) in $40 \mathrm{mM} \mathrm{HCl}$ and $20 \mathrm{mM}$ $\mathrm{FeCl}_{3} \cdot 6 \mathrm{H}_{2} \mathrm{O}$ at the ratio of $10: 1: 1$ to produce the working reagent. For assays, $3950 \mu \mathrm{l}$ of freshly prepared FRAP reagent was mixed with $50 \mu \mathrm{l}$ sample, standard, or blank and incubated for $30 \mathrm{~min}$ before reading absorbance at $595 \mathrm{~nm}$.

\section{Radical scavenging activity}

In the radical scavenging activity (RSA) assay, $3900 \mu \mathrm{l}$ methanolic DPPH solution $(40 \mathrm{mg} / \mathrm{l})$ and $100 \mu \mathrm{l}$ sample extract were mixed, incubated in the dark, and followed the absorbance change at $517 \mathrm{~nm}$. The experiment was performed using different sample concentrations (10-50 mg fresh sample/ml extraction solvent). The experiment was also performed using sample extract of $50 \mathrm{mg}$ fresh sample/ml extraction solvent at different time levels. The decrease in absorbance was monitored until the reaction reached a plateau, graphs were then constructed showing radical scavenging activity versus time. RSA was calculated as $\left(A_{0}-A_{\mathrm{c}}\right) / A_{0}$, where $A_{0}$ is the absorbance of DPPH solution without sample and $A_{\mathrm{c}}$ is the absorbance of DPPH and sample. The efficient concentration $\left(\mathrm{EC}_{50}\right)$ was also calculated as the amount of antioxidant necessary to decrease the initial DPPH by $50 \%$.
Table 1 Physicochemical properties of pink guava fruits.

\begin{tabular}{lcc}
\hline Characteristics & Sungkai variety & Semenyih variety \\
\hline Fruit weight (g) & $257 \pm 73^{\mathrm{a}}$ & $209 \pm 25^{\mathrm{b}}$ \\
Flesh weight (g) & $249 \pm 72^{\mathrm{a}}$ & $202 \pm 25^{\mathrm{b}}$ \\
Seed weight (g) & $8.1 \pm 2.5^{\mathrm{a}}$ & $7.0 \pm 3.2^{\mathrm{b}}$ \\
Fruit volume (ml) & $268 \pm 78^{\mathrm{a}}$ & $216 \pm 40^{\mathrm{b}}$ \\
Specific gravity & $0.96 \pm 0.05^{\mathrm{a}}$ & $0.98 \pm 0.10^{\mathrm{b}}$ \\
Brix & $7.50 \pm 0.39^{\mathrm{b}}$ & $8.57 \pm 0.53^{\mathrm{a}}$ \\
Brix $/ \mathrm{TA}$ & $16.30 \pm 0.91^{\mathrm{b}}$ & $17.1 \pm 1.1^{\mathrm{a}}$ \\
Acidity & $0.46 \pm 0.00^{\mathrm{a}}$ & $0.50 \pm 0.00^{\mathrm{a}}$ \\
Vitamin C (mg/100 g FW) & \\
- Fruit & $135 \pm 28^{\mathrm{b}}$ & $202 \pm 13^{\mathrm{a}}$ \\
- Flesh & $130 \pm 27^{\mathrm{b}}$ & $190 \pm 12^{\mathrm{a}}$ \\
- Skin & $172 \pm 36^{\mathrm{b}}$ & $308 \pm 57^{\mathrm{a}}$ \\
Lycopene (mg/kg) & $40.5^{\mathrm{b}}$ & $52.8^{\mathrm{a}}$ \\
$L$ (lightness) & $48.24^{\mathrm{b}}$ & $49.39^{\mathrm{a}}$ \\
$a^{+}$(redness) & $11.25^{\mathrm{b}}$ & $16.06^{\mathrm{a}}$ \\
$b^{+}$(yellowness) & $13.77^{\mathrm{a}}$ & $10.17^{\mathrm{b}}$ \\
pH & $4.27^{\mathrm{a}}$ & $4.21^{\mathrm{a}}$ \\
\hline
\end{tabular}

Values are means of triplicate samples \pm SD. Different letters in the same row indicate significant differences $(p<0.05)$.

\section{Extraction and determination of flavonoid compounds}

Freeze-dried sample $(0.5 \mathrm{~g})$ was mixed with $10 \mathrm{ml}$ of $2.0 \mathrm{M} \mathrm{HCl}$ in $80 \%$ aqueous methanol using an Ultra-Turrax disperser (IKA, Germany) and the mixture was heated up at $90^{\circ} \mathrm{C}$ for $2 \mathrm{~h}$. The extract was diluted with water and then filtered through a $0.22 \mu \mathrm{m}$ nylon filter (Whatman, Kent, UK) prior to injection into HPLC (Shimadzu, Japan). A sample of $10.0 \mu \mathrm{l}$ was injected to Symmetry-C18 column (Waters, USA) at $40^{\circ} \mathrm{C}$. The mobile phase used was $1 \%$ formic acid (55\%) in methanol at $0.9 \mathrm{ml} / \mathrm{min}$ flow rate for $20 \mathrm{~min}$.

\section{Statistical analysis}

Data collected were statistically analysed using Minitab (14.20) software. A significance level of $p<0.05$ was used.

\section{RESULTS AND DISCUSSION}

\section{Physicochemical properties of pink guava}

Table 1 shows the characteristics of the two Malaysian pink guava fruit varieties. Semenyih had smaller fruit, lower fruit and flesh weight, lower $\mathrm{pH}$ and higher TTA compared to sungkai. Semenyih had a higher sugar/acid ratio than sungkai, which might contribute towards better storability, since low sugar/acid ratio has been shown to be a good indicator for prolonging fruit quality during storage ${ }^{15}$. The 
Table 2 Folin-Ciocalteu index and ferric reducing antioxidant power (FRAP) values for different pink guava fruit fractions from two different varieties (sungkai and semenyih).

\begin{tabular}{lcc}
\hline Fruit fraction & Total phenolic content $^{\dagger}$ & FRAP $^{\dagger}$ \\
\hline Sungkai skin & $671 \pm 32^{\mathrm{b}}$ & $66.9 \pm 3.9^{\mathrm{b}}$ \\
Sungkai fruit & $227.9 \pm 9.8^{\mathrm{e}}$ & $27.1 \pm 1.1^{\mathrm{e}}$ \\
Sungkai flesh & $193.1 \pm 4.9^{\mathrm{f}}$ & $25.8 \pm 1.1^{\mathrm{e}}$ \\
Semenyih skin & $841 \pm 22^{\mathrm{a}}$ & $82.7 \pm 3.2^{\mathrm{a}}$ \\
Semenyih fruit & $383 \pm 33^{\mathrm{c}}$ & $56.3 \pm 1.9^{\mathrm{c}}$ \\
Semenyih flesh & $344.7 \pm 7.6^{\mathrm{d}}$ & $39.2 \pm 1.5^{\mathrm{d}}$ \\
\hline
\end{tabular}

Values are mean \pm SD. Different letters in the same column indicate significant differences $(p<0.05)$.

${ }^{\dagger} \mathrm{mg}$ gallic acid equivalent/100 $\mathrm{g}$ fresh weight.

$* \mu$ Mtrolox equivalent/g fresh weight.

amounts of total ascorbic acid (TAA) in semenyih were significantly higher $(p<0.05)$ than sungkai. TAA contents in the skin of both varieties were significantly higher $(p<0.05)$ compared to their respective fleshes or fruit fractions. Ascorbic acid content of fruits depended highly on the varieties and the cultivation conditions. Distinct varieties of the same fruit type showed significantly different concentrations ${ }^{16}$.

Compared to sungkai, semenyih fruit showed significantly $(p<0.05)$ higher lycopene content that gives the red colour for the pink guava fruit. Wilberg and Rodriguez-Amaya ${ }^{17}$ reported lycopene content in Brazilian pink flesh guava is in a range from $48.20-54.20 \mathrm{mg} / \mathrm{kg}$ fresh ripe fruits. The colour value of sungkai showed significantly $(p<0.05)$ lower redness value $\left(a^{+}\right)$, lower lightness value $(L)$, and higher yellowness value $\left(b^{+}\right)$when compared to semenyih.

\section{Total phenolic content and ferric reducing antioxidant power (FRAP)}

Individual fruit fractions showed a wide variation of their total phenolic content and FRAP value (Table 2). Maximum total phenolic content and FRAP values were obtained for semenyih fruit variety fractions when compared to sungkai variety. Among each variety fractions, skins showed the highest total phenolic content and FRAP values followed by fruit and flesh, respectively. The size of sungkai fruit is much bigger and this may affect the results, in small fruit the ratio of the skin will be higher compared to the total fruit. Total phenolic content and FRAP values for the pink guava fruit in this study were higher than the values reported by Thaipong et $\mathrm{al}^{5}$, Luximon-Ramma et $\mathrm{al}^{18}$, and

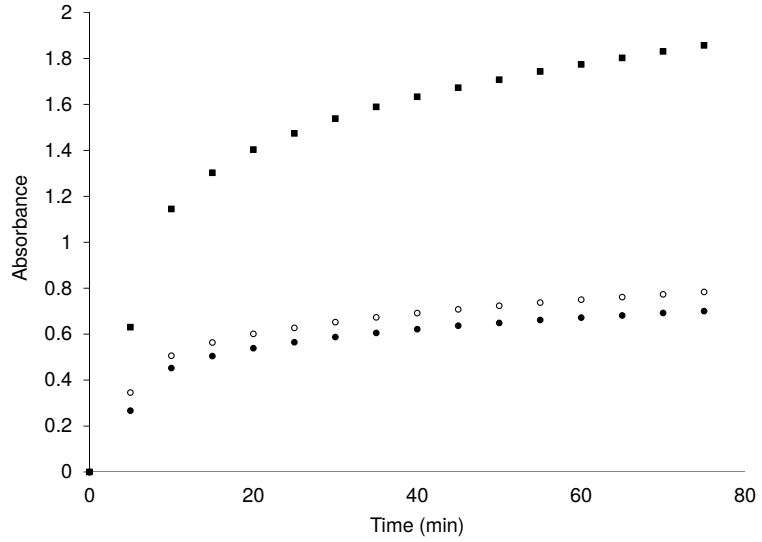

Fig. 1 FRAP reaction kinetics for skin ( $)$, fruit (o), and flesh $(\bullet)$ fractions (sungkai variety), rate of increase in absorbance at $595 \mathrm{~nm}$ for $50 \mathrm{~g} / 1$ solutions of sample.

Guo et $\mathrm{al}^{19}$. Differences in extraction methods and solvent ${ }^{12}$, cultivation location ${ }^{20,21}$, ripening stage ${ }^{22}$, harvested condition and seasons ${ }^{23}$ could be the most likely factors.

In this study the reaction time of FRAP was prolonged and compared to the $4 \mathrm{~min}$ in the original procedure of Benzie and Strain ${ }^{14}$. The rate of the reactions of individual fraction differs substantially (Fig. 1). FRAP value was calculated at $30 \mathrm{~min}$ since the order of antioxidant efficiency of samples were maintained after $30 \mathrm{~min}$. Trolox standards react quickly with FRAP reagent, reaching the maximum in less than 2 min and the absorbance was constant after that. Pulido et $\mathrm{al}^{24}$ observed similar results based on different standards but not plant extracts. The results of our observation are in agreement with published data ${ }^{25,26}$.

\section{DPPH radical scavenging activity of pink guava}

The radical scavenging activity values in Fig. 2 indicate a different activity of each pink guava fruit samples towards the stable free radical. Skin fraction extract reacted faster towards the DPPH radical and the reaction reached the plateau in 2 min for semenyih skin and 3 min for sungkai skin, whereas slow reaction took place for other samples. The flesh fractions in both variety reactions reached the plateau in 4 min for semenyih flesh and 12 min for sungkai flesh. Trolox standards also react quickly towards DPPH radical.

The RSA for pink guava extract at different concentrations are shown in Table 3. As anticipated, the higher the concentration of sample, the higher the scavenging activity. However, at certain concen- 

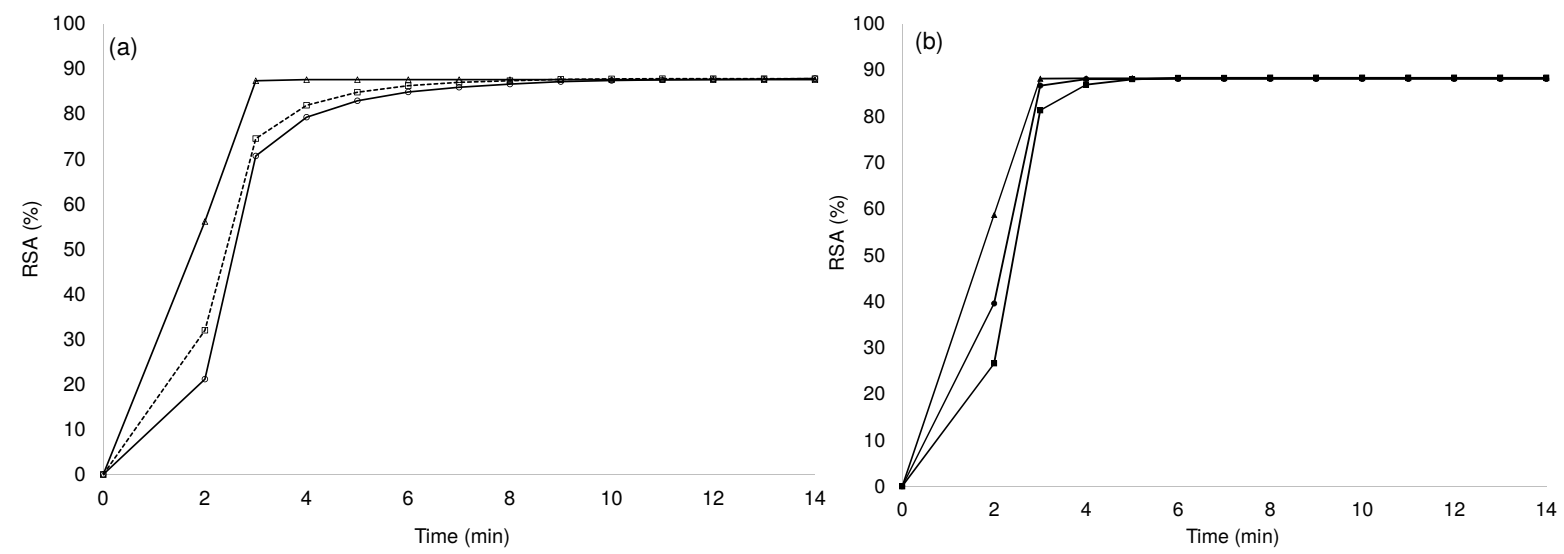

Fig. 2 DPPH radical scavenging activity of (a) sungkai variety and (b) semenyih variety (triangles: skin, squares: fruit, circles: flesh), with rate of increase in activity at $515 \mathrm{~nm}$ for $50 \mathrm{~g} / 1$ solutions of sample.

Table 3 Radical scavenging activity as a function of sample concentration for pink flesh guava fruit.

\begin{tabular}{lrlllll}
\hline Fruit sample & \multicolumn{5}{c}{ RSA (\%) } & $\mathrm{EC}_{50^{\star}}$ \\
\cline { 2 - 6 } & $C=10^{\dagger}$ & 20 & 30 & 40 & 50 & \\
\hline Sungkai skin & $67^{\mathrm{b}}$ & $86^{\mathrm{a}}$ & $86^{\mathrm{a}}$ & $86^{\mathrm{a}}$ & $86^{\mathrm{a}}$ & $7.57^{\mathrm{e}}$ \\
Sungkai fruit & $35^{\mathrm{e}}$ & $52^{\mathrm{d}}$ & $61^{\mathrm{c}}$ & $74^{\mathrm{b}}$ & $83^{\mathrm{b}}$ & $18.91^{\mathrm{b}}$ \\
Sungkai flesh & $35^{\mathrm{e}}$ & $50^{\mathrm{d}}$ & $60^{\mathrm{c}}$ & $69^{\mathrm{c}}$ & $77^{\mathrm{c}}$ & $20.15^{\mathrm{a}}$ \\
Semenyih skin & $74^{\mathrm{a}}$ & $85^{\mathrm{a}}$ & $86^{\mathrm{a}}$ & $86^{\mathrm{a}}$ & $86^{\mathrm{a}}$ & $6.73^{\mathrm{f}}$ \\
Semenyih fruit & $48^{\mathrm{c}}$ & $67^{\mathrm{b}}$ & $80^{\mathrm{b}}$ & $86^{\mathrm{a}}$ & $86^{\mathrm{a}}$ & $10.85^{\mathrm{d}}$ \\
Semenyih flesh & $43^{\mathrm{d}}$ & $62^{\mathrm{c}}$ & $77^{\mathrm{b}}$ & $86^{\mathrm{a}}$ & $87^{\mathrm{a}}$ & $13.57^{\mathrm{c}}$ \\
\hline
\end{tabular}

† Sample concentration (mg fresh sample/ml solvent).

$\star$ Radical scavenging activity expressed as the concentration that reduced the free radicals by $50 \%$ (mg weight/ml extracting solvent).

Different letters in the same column indicate significant differences $(p<0.05)$.

Different letters in the same row, except for the $\mathrm{EC}_{50}$ column, showed significant differences $(p<0.05)$.

trations, there was no increase in the scavenging activity. At higher concentrations of any antioxidant, absorbance will not increase beyond the point at which all the available DPPH free radicals have been consumed. This is reflected in the results, which showed no change in DPPH radical scavenging activity at concentrations above $40 \mathrm{mg}$ fresh sample $/ 1 \mathrm{ml}$ solvent. At high sample concentration, the RSA rank of the antioxidant activity value in the extracted samples was: semenyih skin = sungkai skin $=$ semenyih fruit $=$ semenyih flesh $>$ sungkai fruit $>$ sungkai flesh. Generally, any sample showed scavenging activity value higher than $80 \%$ should be diluted to get better and safer classification of samples. When samples classified by using sam- ples at low concentration $(10 \mathrm{mg} / \mathrm{ml})$ of extract; the rank of the antioxidant activity value in the extracted samples was: semenyih skin $>$ sungkai skin $>$ semenyih fruit $>$ semenyih flesh $>$ sungkai fruit $=$ sungkai flesh.

Results from single concentration may not be directly used in comparing between radical scavenging activities of different samples. The use of different sample concentrations may result in more information about antioxidant extracts. The radical scavenging activity was reported as percentage as effective concentration $\left(\mathrm{EC}_{50}\right)$ and compared to RSA. Sample extracts were easily and clearly classified when $\mathrm{EC}_{50}$ was used. The rank of the antioxidant activity values in fruits was: semenyih skin $>$ sungkai skin $>$ semenyih fruit $>$ semenyih flesh $>$ sungkai fruit $>$ sungkai flesh.

The $\mathrm{EC}_{50}$ value is more convenient than the kinetic version but it does not give any information about the rapidity of the kinetics. However, using $\mathrm{EC}_{50}$ requires more numbers of samples and work compared to RSA which is convenient, and save time and chemicals. RSA could be used for screening purposes while $\mathrm{EC}_{50}$ could be used for sample classification and details.

\section{Flavonoids in pink guava fruit}

Kaempferol was the dominant flavonoid in fruits and quercetin was the minor flavonoid in both varieties (Fig. 3). The total flavonoid content was significantly higher $(p<0.05)$ in sungkai fruit and flesh compared to semenyih; while semenyih skin was higher $(p<0.05)$ compared to sungkai skin. As for luteolin, both sungkai and semenyih fruit showed no significant difference $(p<0.05)$ in their luteolin content while sungkai flesh and semenyih skin both 


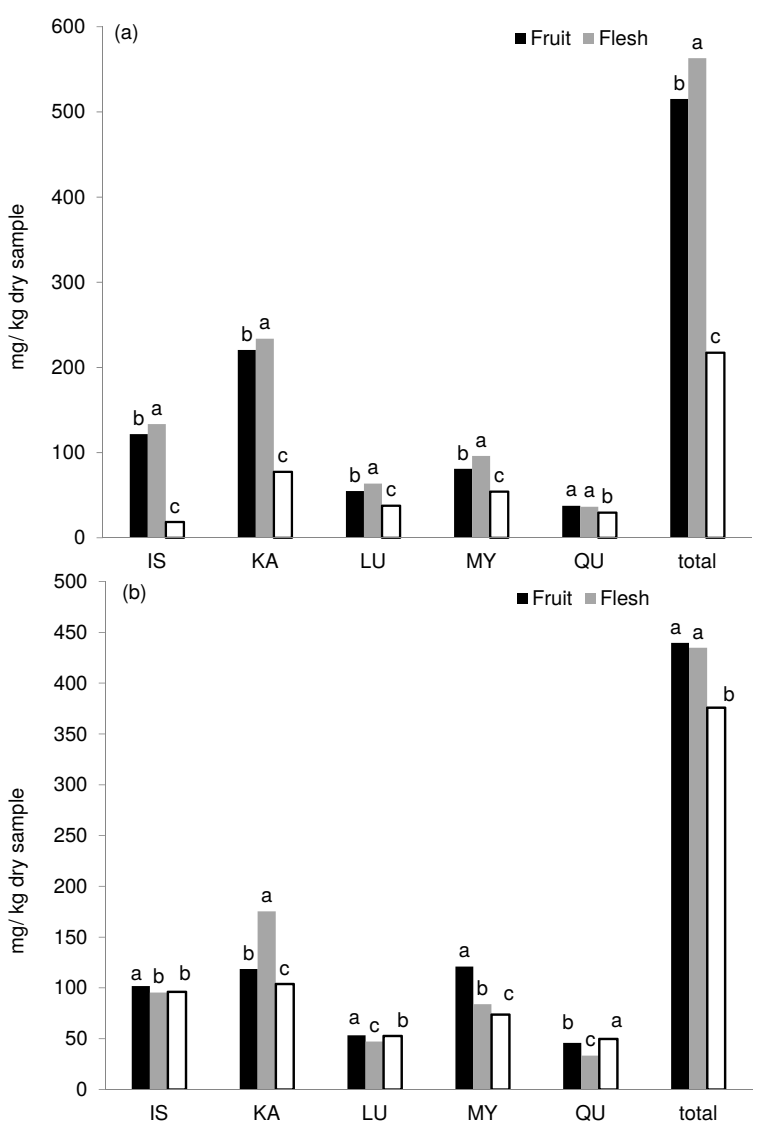

Fig. 3 Flavonoid contents in pink guava fruit fractions of sungkai variety (a) and semenyih variety (b). The flavonoids detected were myricetin (MY), quercetin (QU), luteolin (LU), kaempferol (KA), and isorhamentin (IS). Means of each flavonoid marked by the same letter are not significantly different at $p<0.05$.

showed higher values. The levels of myricetin in sungkai fruit, flesh, and skin were 80.38, 93.75, and $51.60 \mathrm{mg} / \mathrm{kg}$, respectively, and for semenyih the levels were $83.05,84.00$, and $73.75 \mathrm{mg} / \mathrm{kg}$ for fruit, flesh, and skin, respectively. Apigenin was not detected in all fractions from both fruit varieties which is in agreement with published work ${ }^{27}$.

\section{Conclusion}

Pink guava shows valuable nutraceutical properties in terms of high antioxidant activity as well as vitamin $\mathrm{C}$ and lycopene. The flavonoid content is reported with kaempferol as the main flavonoid compound. Moreover, since these fruits show the highest antioxidant content in the peel, they seem to be particularly suitable for unpeeled whole fresh fruit consumption and thus promote health related benefits.
Acknowledgements: This study was supported by Universiti Kebangsaan Malaysia under project no. STGL 0042006.

\section{REFERENCES}

1. Halliwell B (1999) Establishing the significance and optimal intake of dietary antioxidants: the biomarker concept. Nutr Rev 57, 104-13.

2. Boyer J, Liu RH (2004) Apple phytochemicals and their health benefits. Nutr $J$ 3, 5 .

3. Eberhardt MV, Lee CY, Liu RH (2000) Nutrition: antioxidant activity of fresh apples. Nature 405, 903-4.

4. Chopda CA, Barrett DM (2001) Optimization of guava juice and powder production. $J$ Food Process Pres 25, 411-30.

5. Thaipong K, Boonprakob U, Crosby K, CisnerosZevallos L, Hawkins-Byrne D (2006) Comparison of ABTS, DPPH, FRAP, and ORAC assays for estimating antioxidant activity from guava fruit extracts. $J$ Food Compos Anal 19, 669-75.

6. Kwee LT, Chong KK (1990) Guava in Malaysia: Production, Pests and Diseases, Tropical Press Sdn. Bhd, Kuala Lumpur.

7. Mercadante AZ, Steck A, Pfander H (1999) Carotenoids from guava (Psidium guajava L.): isolation and structure elucidation. J Agr Food Chem 47, 145-51.

8. Padula M, Rodriguez-Amaya DB (1986) Characterisation of the carotenoids and assessment of the vitamin A value of Brasilian guavas (Psidium guajava L.). Food Chem 20, 11-9.

9. Razzaque M, Saud Z, Absar N, Karin M, Hashinaga F (2000) Purification and characterization of polyphenoloxidase from guava infected with fruit-rot disease. Pakistan J Biol Sci 3, 407-10.

10. Fish WW, Perkins-Veazie P, Collins JK (2002) A quantitative assay for lycopene that utilizes reduced volumes of organic solvents. J Food Compos Anal 15, 309-17.

11. Chang CH, Lin HY, Chang CY, Liu YC (2006) Comparisons on the antioxidant properties of fresh, freezedried and hot-air-dried tomatoes. J Food Eng 77, 478-85.

12. Musa KH, Abdullah A, Jusoh K, Subramaniam V (2011) Antioxidant activity of pink-flesh guava (Psidium guajava L.): effect of extraction techniques and solvents. Food Anal Meth 4, 100-7.

13. Slinkard K, Singleton VL (1977) Total phenol analysis: automation and comparison with manual assays. Am J Enol Viticult 28, 49-55.

14. Benzie IF, Strain JJ (1996) The ferric reducing ability of plasma (FRAP) as a measure of "antioxidant power": the FRAP assay. Anal Biochem 239, 70-6.

15. Lee J, Jnn CE, Wrolstad RE (2004) Comparison of anthocyanin pigment and other phenolic compounds of Vaccinium membranaceum and Vaccinium ovatum 
native to the Pacific Northwest of North America. J Agr Food Chem 52, 7039-44.

16. Franke AA, Custer LJ, Arakaki C, Murphy SP (2004) Vitamin $\mathrm{C}$ and flavonoid levels of fruits and vegetables consumed in Hawaii. J Food Compos Anal 17, $1-35$.

17. Wilberg VC, Rodriguez-Amaya DB (1995) HPLC quantitation of major carotenoids of fresh and processed guava, mango and papaya. LWT Food Sci Tech 28, 474-80.

18. Luximon-Ramma A, Bahorun T, Crozier A (2003) Antioxidant actions and phenolic and vitamin $C$ contents of common Mauritian exotic fruits. J Sci Food Agr 83, 496-502.

19. Guo C, Yang J, Wei J, Li Y, Xu J, Jiang Y (2003) Antioxidant activities of peel, pulp and seed fractions of common fruits as determined by FRAP assay. Nutr Res 23, 1719-26.

20. Wang SY, Zheng W, Galletta GJ (2002) Cultural system affects fruit quality and antioxidant capacity in strawberries. J Agr Food Chem 50, 6534-42.

21. Häkkinen SH, Törrönen AR (2000) Content of flavonols and selected phenolic acids in strawberries and Vaccinium species: influence of cultivar, cultivation site and technique. Food Res Int 33, 517-24.

22. Raffo A, et al (2002) Nutritional value of cherry tomatoes (Lycopersicon esculentum cv. Naomi F1) harvested at different ripening stages. $J$ Agr Food Chem 50, 6550-6.

23. Wu X, Gu L, Holden J, Haytowitz DB, Gebhardt SE, Beecher G, Prior RL (2004) Development of a database for total antioxidant capacity in foods: a preliminary study. J Food Compos Anal 17, 407-22.

24. Pulido R, Bravo L, Saura-Calixto F (2000) Antioxidant activity of dietary polyphenols as determined by a modified ferric reducing antioxidant power assay. J Agr Food Chem 48, 3396-402.

25. Imeh U, Khokhar S (2002) Distribution of conjugated and free phenols in fruits: antioxidant activity and cultivar variations. J Agr Food Chem 50, 6301-6.

26. Stratil P, Klejdus B, Kuban V (2006) Determination of total content of phenolic compounds and their antioxidant activity in vegetables evaluation of spectrophotometric assays. J Agr Food Chem 54, 607-61.

27. Misra K, Seshadri TR (1968) Chemical components of the fruits of Psidium guajava. Phytochemistry 7, 641-5. 